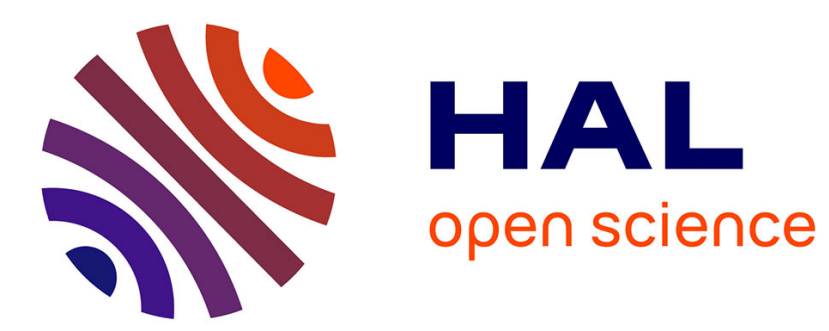

\title{
E-BRAILLE DOCUMENTS: NOVEL METHOD FOR ERROR FREE GENERATION
}

\author{
Mohd Wajid, Vinay Kumar
}

\section{To cite this version:}

Mohd Wajid, Vinay Kumar. E-BRAILLE DOCUMENTS: NOVEL METHOD FOR ERROR FREE GENERATION. Image Processing and Communications, 2015, 19 (4), pp.21-26. 10.1515/ipc-20150021 . hal-01154363

\author{
HAL Id: hal-01154363 \\ https://hal.inria.fr/hal-01154363
}

Submitted on 21 May 2015

HAL is a multi-disciplinary open access archive for the deposit and dissemination of scientific research documents, whether they are published or not. The documents may come from teaching and research institutions in France or abroad, or from public or private research centers.
L'archive ouverte pluridisciplinaire HAL, est destinée au dépôt et à la diffusion de documents scientifiques de niveau recherche, publiés ou non, émanant des établissements d'enseignement et de recherche français ou étrangers, des laboratoires publics ou privés. 


\title{
E-BRAILLE DOCUMENTS: NOVEL METHOD FOR ERROR FREE GENERATION
}

\author{
MOHD WAJID $^{1}$ VINAY KUMAR ${ }^{2}$ \\ ${ }^{1}$ Department of Electronics and Communication Engineering, JUIT, Solan, India \\ mohd.wajidejuit.ac.in, \\ ${ }^{2}$ Electronics and Communication Engineering Department, Thapar University, Patiala \\ vinay.kumar@thapar.edu
}

\begin{abstract}
Present manuscript proposes a technique for estimating the angle of rotation for a Braille document image which in turn will be used for aiding its automatic character recognition. The technique is based on maximizing number of null projection of the derived image vector. Results show that any amount of rotation transformed distortion can be nullified and thus leading to proper reading of imprinted Braille character pattern. The proposed methods have been successfully tested on manually written as well as computer generated Braille with rotation distortion.
\end{abstract}

\section{Introduction}

In the era of internet and e-books there is a dire need for the development of Braille e-libraries to make sure that visually challenged people can use the power of internet like any other person. Proposed manuscript aids in the fast conversion of Braille text with the help of photographed or scanned images to Braille e-content.
Braille system is a well developed method for written communication for visually challenged people for almost all the languages in the world. A Braille character can be seen as embossed dot pattern on thick paper that can be sensed with fingers. The size of the raised dot is significantly big to make sure that they provide easy perception by finger. For people with visual capabilities these dot patterns can be recognized and subsequently deciphered. In other words, Braille dot pattern is a coding scheme; for each character of a language it has unique dot pattern. The Braille dots (corresponding to alphabets) are embossed in a region of standard area called Braille cells. Each cell contains maximum six dots as shown in Fig. 1.

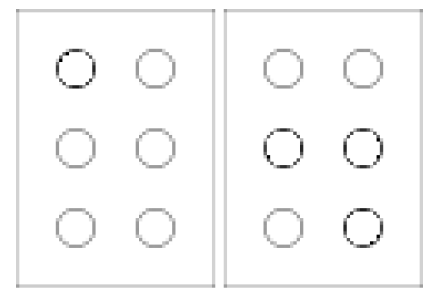

Fig. 1: Braille pattern

There are total six positions where at most 6 dots can 
be placed; the total number of patterns that can be formed is sixty-four including a null set

$$
\text { Number of dot patterns }=\sum_{r=0}^{6} C_{6}^{r}
$$

In $[4,2,3]$ the authors have developed a method for automation of converting word document/print into Braille and vice-verse. The methods in these manuscripts are table driven and does the job of conversion from/to Braille to/from corresponding language. In [5] hardware Braille pad is discussed which allows reading text document from computer by means of tactile perception. The proposed technique is converting already available patterns (in image format) of Braille to the corresponding binary vector for electronic transfer or e-Braille readers [1]. They can be printed as Braille patterns or may be read using a Braille e-reader.

In [6] the author has developed a method for automatic recognition of Braille pattern from its Braille image with many applications; like, teaching/learning Braille to visually challenged children, for machine driven correction of examination script in Braille, for secret communication and also in creation of e-library for Braille. Creation of images, either by scanning or photography, may have rotational distortion, which make the decoding of these patterns difficult. In the present manuscript we have developed a methodology to correct these rotation transform distortion. This will help and speed up (since this will eliminate the need of scanning the images with zero rotation; also we may use faster mechanism of photography) in creation of digital content for Braille, which may later be produced in printed or e-book form for visually challenged people. It will also make it possible to convert Braille images into Braille text [4, 2, 3].

\section{E-Braille documentation}

To generate electronic files for Braille documents we first capture images of these documents with a camera. Since
Braille documents have only dot patters camera specifications need not to be very high, together with that our algorithm takes care of small noisy patters introduced during the capture process. Now we elaborate upon the proposed algorithm step-wise in rest of the section.

For the recognition of the Braille image we first have to pre-process the image. The preprocessing steps helps in removing unwanted edges or noise from the pattern. Following steps are undertaken for pre-processing:

1. Scan the Braille in binary form (in case we choose to capture an image with camera Step 2 will be required for faster processing)

2. Convert RGB image to binary image (not required if scanned in binary format)

3. Removal of the impulse noise and dots (which are not part of Braille pattern)

4. Remove unwanted redundant edges of the image [6].

Step three can be carried out by computationally nonexpensive morphological filters. On pre-processed image following algorithm is applied

The method proposed in [6] for recognition of Braille character pattern produces erroneous results when the Braille image is 'not' aligned while scanning. A fast methodology for performing the digitization is capturing images with the help of a camera. Unless the document is not places properly aligned with the camera a rotational error will appear. We have tested the robustness against Braille image rotation; say the image is rotated with an angle $\theta$. Whenever $|\theta|$ is $>1.5^{\circ}$ the correct vector associated with the Braille character is not produced. Our proposed correction makes it robust for any amount of rotation. 


\section{Proposed procedure for estima- tion of rotation angle}

We first estimate rotation angle $\hat{\theta}$. This estimation will be utilized to perform reverse rotation transformation for image alignment and proper recognition of Braille character patterns.

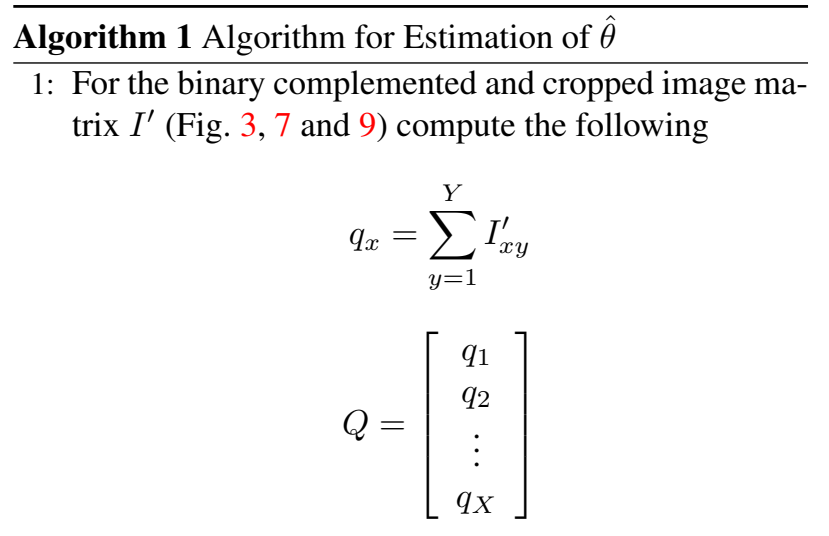

where, $(X, Y)$ is the order of the matrix $I^{\prime}$ and $Q$ is the derived column vector in $R^{X}$ space.

2: Compute $\tilde{Q}=Q-\delta Q$; where, $\delta Q$ is the threshold noise vector and is equal to null vector for other than first iteration.

3: For the vector $\tilde{Q}$, compute the Number of Null Projections $(N N P)$ in the space $R^{X}$ and the number of zero elements in $\tilde{Q}$, will be equal to $N N P$.

4: Perform rotation transformation by $\delta \theta$ in anticlockwise direction and crop the unwanted boundary region [6] and store the result in the same variable $I^{\prime}$, mathematically we can say

$$
\begin{gathered}
I^{\prime \prime}=\operatorname{crop}\left[R_{-\delta \theta} I^{\prime}\right] \\
I^{\prime}=I^{\prime \prime}
\end{gathered}
$$

The minus sign in the above equation indicates that, if $R_{\theta}$ is a causes of rotation in clock wise direction then $R_{\delta \theta}$ is also a rotation in clockwise direction by an amount of $\delta \theta$, since we are interested in anticlockwise rotation by $\delta \theta$ we make it with a minus sign. This will change order of $I^{\prime}$.

5: Repeat Step 2 to 5, until $N N P$ maximizes.

6: $\hat{\theta}=n \delta \theta$, where $n$ is number of iterations.

7: $I^{\prime}$ is the final corrected image after inverse rotation transform by angle $\hat{\theta}$.

Assume that Braille image $I$ is deformed while scan- ning (or photographing) by rotation transformation with angle $\theta$ in clockwise direction, refer Figs. 3, 7 and 9. The deformed image is represented by $I^{\prime}$.

$$
\begin{gathered}
I^{\prime}=\operatorname{crop}\left[R_{\theta} I\right] \\
\left(\begin{array}{l}
x^{\prime} \\
y^{\prime}
\end{array}\right)=\left(\begin{array}{ll}
\cos \theta & \sin \theta \\
-\sin \theta & \cos \theta
\end{array}\right)\left(\begin{array}{l}
x \\
y
\end{array}\right)
\end{gathered}
$$

where, $R_{\theta}$ is the rotation transformation matrix with rotation angle of $\theta$ degree and crop is used to eliminate the border from text for better application of the proposed methodology [6]. For clockwise rotation with angle $\theta$ the pixel at location $(x, y)$ will be moved to the pixel at location $\left(x^{\prime}, y^{\prime}\right)$.

Stepwise procedure for estimation of angle $\hat{\theta}$ is as follows.

\section{Results}

For the scanned Braille image of Fig. 2 distorted with angles $5^{\circ}, 2^{\circ}, 0.125^{\circ}$, and $0^{\circ}$, the plot of vector $Q$ is shown in Figs. 10 to 13 and associated NNP verses angle of correction for the images in Fig. 3, 7 and 9 is shown in Figs. 14 to 16.

Fig. 2: Computer Generated BrailleŠs binary image

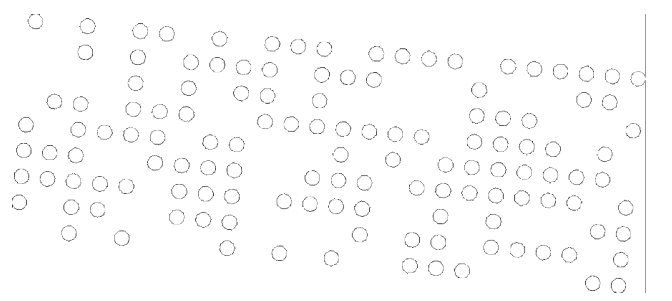

Fig. 3: Computer generated binary image rotated by angle $5^{\circ}$ with cropped unwanted region 


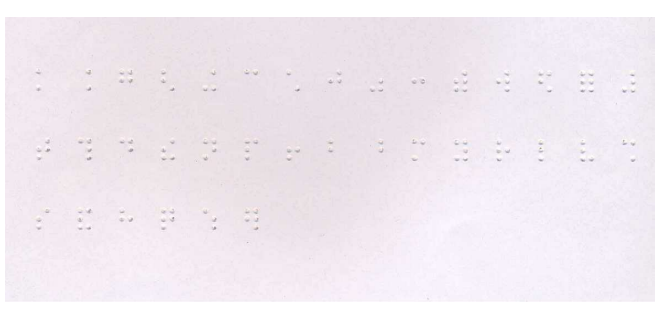

Fig. 4: Manual, original, Braille Image 1

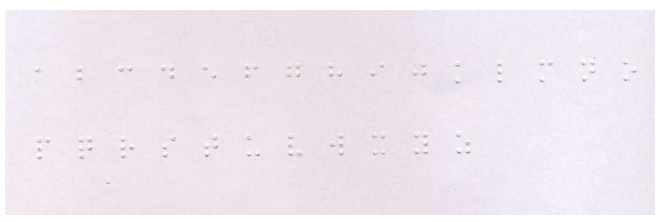

Fig. 5: Manual, original, Braille Image 2

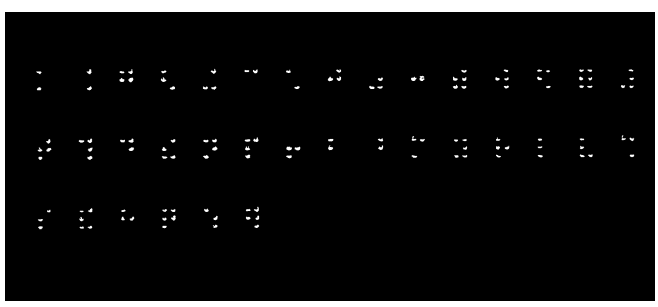

Fig. 6: Braille's binary image corresponding to Image 1

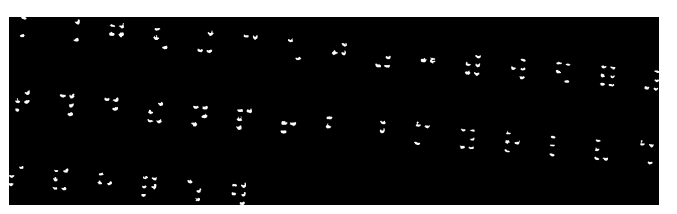

Fig. 7: Manual Braille's binary Image 1 rotated by an angle $5^{\circ}$

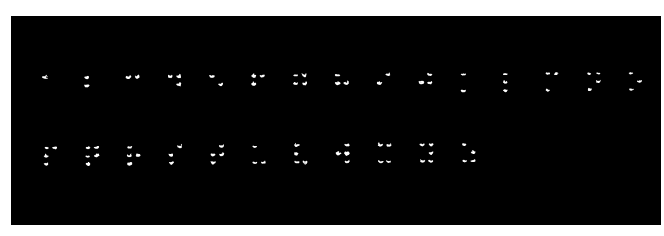

Fig. 8: Braille's binary image corresponding to Image 2

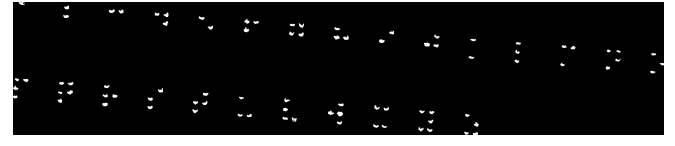

Fig. 9: Manual Braille's binary Image 2 rotated by an angle $5^{\circ}$ with croping [4]

\section{Conclusion}

The proposed technique for estimation of Braille image rotation angle is tested on computer generated image as well as manually written Braille patterns and verified for its robustness against various rotation angles. The maximum error we are receive in the present process is less than $0.4^{\circ}$, and the available Braille reader is robust for an error $|\theta| \leq 1.3^{\circ}$. Therefore, this add on process (proposed technique) is sufficient for the automatic Braille reader.

The proposed technique presents a completely robust, error free and simple method for conversion of Braille documents into electronic Braille patterns. These patterns may be used for the development of e-libraries (for later printing ot Braille e-book readers).

\section{References}

[1] Bar-Cohen, Y. (2009). Electroactive polymers for refreshable Braille displays. SPIE Newsroom, 11.

[2] Blenkhorn, P. (1997). A system for converting print into braille, IEEE Transactions on Rehabilitation Engineering, 5(2), 121-129

[3] Blenkhorn, P. (1995). A system for converting braille into print, IEEE Transactions on Rehabilitation Engineering, 3(2), 215-221

[4] Paul, B., Gareth, E. (2001). Automated braille production from word-processed documents, IEEE transactions on Neural Systems and Rehabilitation Engineering, 9(9), 81-85

[5] Supriya, S., Senthilkumar, A. (2009). Electronic 


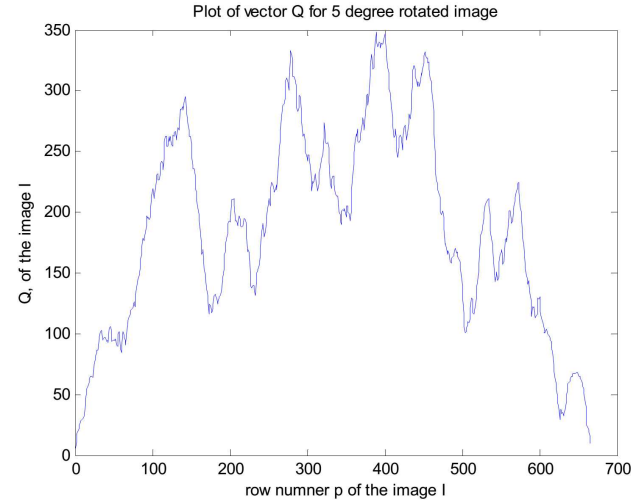

Fig. 10: Plot for vector $Q$ for $5^{\circ}$ rotated image

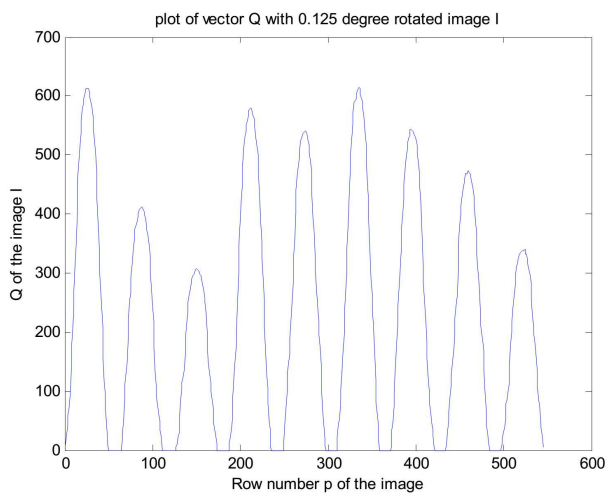

Fig. 12: Plot for vector $Q$ for $0.125^{\circ}$ rotated image

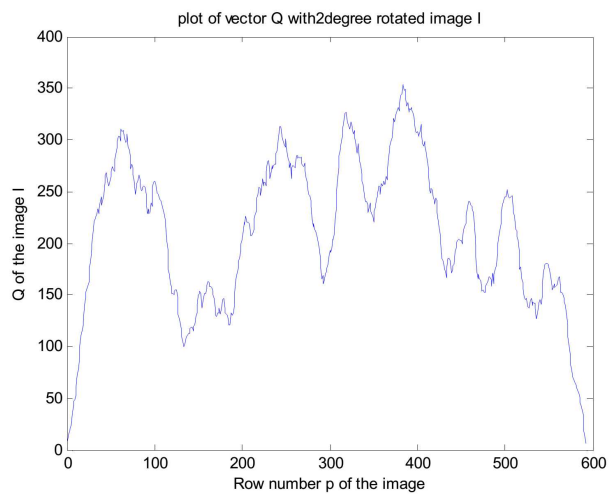

Fig. 11: Plot for vector $Q$ for $2^{\circ}$ rotated image

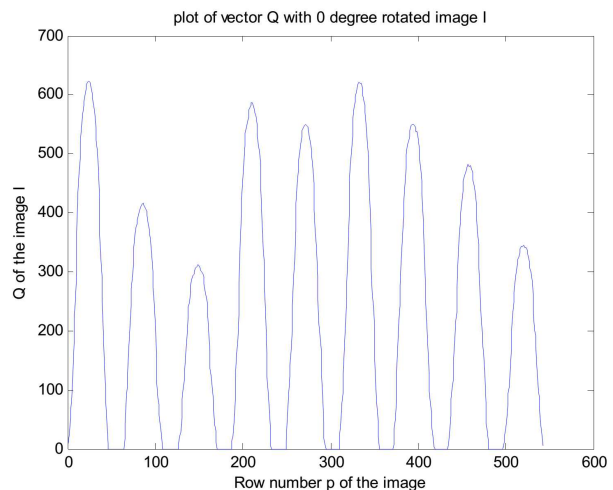

Fig. 13: Plot for vector $Q$ for $0^{\circ}$ rotated image

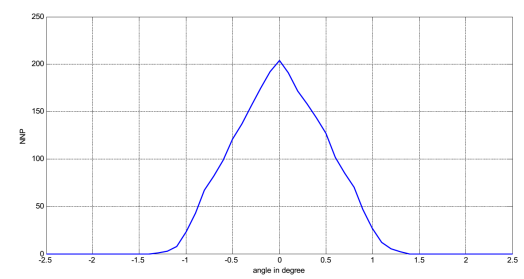

Fig. 14: NNP vs angle of correction for image in Fig. 3

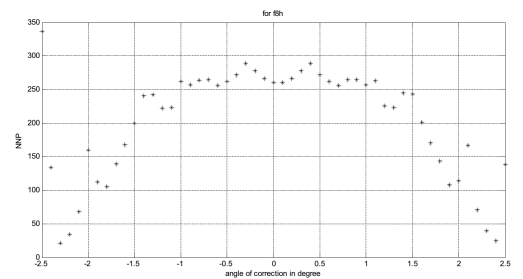

Fig. 15: NNP vs angle of correction for image in Fig. 7

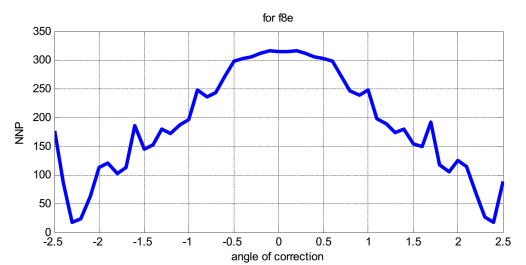

Fig. 16: NNP vs angle of correction for image in Fig. 9 
Braille pad. In Control, Automation, Communication and Energy Conservation, 2009. INCACEC 2009. International Conference on IEEE. 1-5

[6] Wajid, M., Abdullah, M. W., Farooq, O. (2011). Imprinted Braille-character pattern recognition using image processing techniques. In Image Information Processing (ICIIP), 2011 International Conference on IEEE. 1-5 